erved by the studio at Lugano. In order to meet the equirements for music transmission, circuits having a cut-off frequency of 10,000 are provided. This enables a sound spectrum of $35-7500$ cycles per second to be obtained without distortion. In addition, there exist lightly loaded circuits having a cut-off frequency of 6800 cycles, giving a range of $150-5000$ cycles for broadcast speech transmission. At present 87 per cent of all the toll circuits are in underground cable.

\section{Broadcasting and Television in France}

La Nature for Sept. 1 is devoted exclusively to an inquiry on television and broadcasting. The views of several eminent technicians both in France and other countries are given. Manfred von Ardenne takes an optimistic view of the progress of television in Germany and looks forward to a great increase in the art before next winter. Maps are given showing a national scheme for radio diffusion in France and comparing it with the present system. A description is given of the new short-wave transmitter in Berlin, the largest in the world. Power of 15 kllowatts is emitted by waves seven metres long. It will help in the solution of certain problems in television and in producing broadcasting free from disturbance. The legal aspects of the problems which arise when a 'listener' is disturbed by induction from apparatus working in the neighbourhood are considered at length. Several law cases are quoted which show that the rights of listeners are recognised in France, and that those who use apparatus which interferes with the working of a private user's set are liable to substantial fines. The disturbances may be due to an electric motor driving a gramophone, neon tube lighting, the working of a cinema, the electric bell system on the ground floor, and public electric supply systems. In certain cases the use of devices to prevent interference is enforced. In conclusion, the influence of American improvements on the design of French receiving sets is discussed.

\section{An Early Diffraction Grating}

The June issue of the Journal of the Franklin Institute contains two interesting letters from the second volume of the Transactions of the American Philosophical Society (1786), from which it would appear that a transmission grating had been used to produce spectra prior to the work of Fraunhofer (1820). The first, which is addressed to David Rittenhouse from F. Hopkinson, of Philadelphia, has a description of the appearance presented when a street lamp is viewed through a silk handkerchief, and contains a request for an explanation of the pattern formed. The second, dated eleven months later, is Rittenhouse's reply. From its contents, and the lapse of time from the first letter, it appears that he had given considerable thought to the matter. Starting with the observation that the experiment is more curious than one would at first imagine, Rittenhouse then describes the grating he made to perform it with more accuracy. He constructed a square of parallel hairs, about half an inch each way, laid into the threads of two fine screws, with a pitch of 106 to the inch, which he had cut from brass wire. With this he observed a small opening in the window shutter in a dark room, at first with the unaided eye, and later with a prismatic telescope and micrometer, to measure the angular separation in units of the pattern. Six orders of diffraction were observed on either side of the zero, and measured up, and he noted that the dispersion of colours was in the opposite sense to that obtained with a prism, which he considered parallel to Newton's observations on the colours of fringes at the edges of shadows. Rittenhouse was unable to carry out the calculation of wave-lengths from his observations, as Fresnel's theory of diffraction did not appear until 1815 , but his data lead to quite good results : $6200 \mathrm{~A}$. for the red, and $4600 \mathrm{~A}$. for the blue. He does not appear to have followed the work up further, so far as this correspondence goes. Fraunhofer's work was of course the more complete, but this experiment is interesting as coming in the gap between the time of Newton and that of the great optical researches of the early nineteenth century.

\section{Hydro-electric Power on the Dnieper}

A REPORT from Washington states that " Dneprostroy" was dedicated on Aug. 25. This hydro-electric power project on the Dnieper River, with a capacity of 756,000 h.p., is the largest in the world. The power will be available for metallurgical and chemical industries and to irrigate the rich but droughty steppes. Ships from the Black Sea will now be able to penetrate hundreds of miles farther inland. The cost is approximately $110,000,000$ dollars, and the dam, the largest ever constructed, was constructed ahead of the schedule. The dam is 3350 feet long and 140 feet high to the crest of the spillway, above which water may rise 30 feet during floods. The structure impounds a flow varying from 6300 to $835,000 \mathrm{cu}$. ft. a second at times of large freshets. Six of the nine power units are now being installed. The turbines have a rated capacity of 84,000 h.p., and 100,000 h.p. under a maximum head of water. The maximum or high-water capacity is 900,000 h.p., but owing to irregular flow, only three of the units can be operated during the entire year.

\section{Agriculture in the East of England}

THE report on an " Economic Survey of Agriculture in the Eastern Counties of England " issued by the Department of Agriculture, University of Cambridge, and published by Messrs. Heffer and Sons, Cambridge, price 2s. 9d. post paid, presents an analysis of the financial results for 1931 of nearly a thousand farms in the province. During the year farmers in this area experienced heavy losses. The general price level of agricultural produce averaged 18 per cent below that necessary to provide occupiers with a reasonable return for their own labour and capital investment. The majority of those farmers who were fortunate enough to secure a profit enjoyed special marketing facilities, retailed milk or concentrated on the production of livestock and livestock products, or both. As the eastern counties are generally described as a graingrowing area, it is rather surprising to find that while sales of cereals amounted to less than 14 per cent of the gross income, sales of livestock and their products

$$
\text { No. 3283, VoL. 130] }
$$


represented nearly 70 per cent. The very low prices obtainable for the 1931 cereal crops influence these proportions, but even taking this into consideration, cereals can be described as an important cash product on the larger farms only. The success of the small farmer, and these form the majority, is more dependent on the price of livestock and feeding stuffs than on those of cereals. Interesting comparisons are made of the organisation of the agriculture of the principal farming localities of the province: for example, central Norfolk light loams, the Norfolk 'breck', central Suffolk heavy soils, south Essex London clays, south Cambridgeshire gravels, etc. The most depressed areas are the boulder clays of Essex and Suffolk, and the clays in west Cambridgeshire and Huntingdonshire. The report deals further with main factors influencing profits and with many other subjects of interest to administrators and to farmers.

\section{Electricity and the Farmer}

A PAPER read by F. E. Rowland at the Royal Agricultural Show, Southampton, on July 7 and printed by the B.E.D.A. (British Electrical Development Association, Inc.) of 15 Savoy Street, W.C.2, gives helpful hints to farmers as to the best way to apply electricity to their farms. The price of the unit is taken as $2 d$., and when it can be obtained at this price a good case is made out for using electric power. In many cases when space is limited, as in stackyards, electric drive has many advantages. 18 sheep can be sheared per unit expended, or 45 horses groomed, or 12 horses clipped. Motors can be rolled from one part of a farm to another inside wooden drums. Excellent and economical methods are given of lighting farm buildings and roads. Electrically driven pumps provide automatically a plentiful supply of water for all purposes. The use of electric milkers which require a $\frac{1}{2}-h . p$. motor is becoming widespread in England. In New Zealand 15,000 are in use. By the expenditure of one electric unit, 22 cows can be milked, $120 \mathrm{lb}$. of butter churned, or 1000 bottles washed. Accurate data are given as to the effect of poultry lighting in stimulating egg production.

\section{A New Journal of Animal Ecology}

$\mathrm{IT}_{\mathrm{T}}$ is gratifying to find that zoological analysis, having for long been largely confined to the laboratory, is being pushed with vigour into the open country, the obvious place for testing and resolving some of the big problems of animal life. So insistent has been the demand for space to publish the results of observations upon animal populations, their distribution, fluctuations in numbers, migrations and the like, and to concentrate observations of the kind for the convenience of field-workers and zoologists in general, that the British Ecological Society has decided to issue, twice a year, a Journal of Animal Ecology, under the editorship of Charles Elton, assisted by A. D. Middleton. The first number, which appeared in May from the Cambridge University Press, is an attractive volume, in appearance as well as in matter. It contains many-sided contributions, from studies of the fluctuations of insect populations in wheat and of bird numbers on an Oxfordshire farm, to a rookery census, an analysis of the ranging habits of wood-ants, and an account of the biology of the fruit-bats of Australia. There are many illustrations, and a useful reference list contains summaries of papers dealing with animal ecology. Members of the British Ecological Society (Secretary, Dr. H. Godwin, Botany School, Cambridge) obtain the Journal for their subscription of $25 s$., to non-members the price is $30 s$. The magazine promises to make a niche of its own in British zoological literature, and the interest of its outlook ought to draw many supporters. We understand that so far as suitable material is concerned its success is assured.

\section{Acta Phaenologica}

THE new bi-monthly international journal Acta Phaenologica aims at concentrating the hitherto scattered studies in phenology and offering an opportunity to "set forth various tendencies, stages of development, points of view of different centres of phenological experiment, and by giving a chance to consult on aims and methods, to achieve useful and active collaboration ". The journal is issued under the editorship of the board of the Phenological Association of the Netherlands, and in the first part (Sept. 1931: Publ. Martinus Nijhoff, The Hague) the Secretary, Dr. H. Bos, writes on the scope and prospects of phenology. In the same number there are articles by J. Edmund Clarke on "The Cold Spring of 1929 in the British Isles" and S. Illichevsky on "The Results of the Phenological Observations at Poltava (U.S.S.R.)". The second part includes contributions from Prof. Thne on "The Beginning of the Phenological Spring in Central Europe during the Ten Years' Period, 1921-1930", Prof. Poggenpohl on "Phenological Observations, 1886-1907", and Dr. H. Bos on "The Dropping of Small Fruits after Blooming ". Contributions are accepted in English, French, or German, and each is accompanied by a translation of its title and a short summary of the contents in the two other languages.

\section{Habits of the Woodpecker}

Although a tame woodpecker is mentioned by Aristotle, the birds of this family have never been favourites with aviarists, and even the London Zoological Society, after having exhibited at different times no less than seventeen species, had been without a specimen for years until a family of the British greater spotted species arrived recently, and were accommodated with a special cage in the Bird House. Here they attract attention by their extreme activity, which is very characteristic of woodpeckers ; they contrast in this respect with their nearest allies the barbets, of which several species are on view, much as tits do with finches. It is of interest to note, however, that the pair-toed feet, often supposed to be an adaptation for climbing, are to be found in the more primitive group of barbets, which do not climb, and that these peck wood when excavating a nesthole, although their beaks are not specialised into the chisel-type of the woodpeckers' bills, and they do not

$$
\text { No. 3283, Vor. 130] }
$$

